\title{
Development of Alcohol Use Disorder in Young Swiss Men: The Influence of Retrospectively Perceived Parenting Profiles
}

\author{
Sophie Baudat ${ }^{\mathrm{a}, \mathrm{b}}$, Katia Iglesias ${ }^{\mathrm{c}}$, Joseph Studer ${ }^{\mathrm{d}}$, Gerhard Gmel ${ }^{\mathrm{d}, \mathrm{e}, \mathrm{f,g}}$, Stéphanie Baggio ${ }^{\mathrm{a}, \mathrm{h}}$ \\ ${ }^{a}$ Division of Prison Health, Geneva University Hospitals and University of Geneva, Chemin du Petit \\ Bel Air 2, 1226 Thônex, Switzerland \\ ${ }^{b}$ Family and development research center, Institute of Psychology, University of Lausanne, Geopolis \\ Building, 1015 Lausanne, Switzerland \\ ${ }^{\mathrm{c}}$ School of Health Sciences, HES-SO University of Applied Sciences and Arts of Western \\ Switzerland, Route des Arsenaux 16a, 1700 Fribourg, Switzerland \\ d Addiction Medicine, Department of Psychiatry, Lausanne University Hospital and University of \\ Lausanne, Rue du Bugnon 23, 1011 Lausanne, Switzerland \\ e Addiction Switzerland, Avenue Louis-Ruchonnet 14, 1003 Lausanne, Switzerland \\ ${ }_{\mathrm{f}}$ Centre for Addiction and Mental Health, 1001 Queen Street West, Toronto ON - M6J 1H4, Canada \\ ${ }^{\mathrm{g}}$ University of the West of England, Coldharbour Ln, Stoke Gifford, Bristol BS16 1QY, UK \\ ${ }^{\mathrm{h}}$ Department of Forensic Psychiatry, Institute of Forensic Medicine, University of Bern, Falkenplatz \\ 16, 3012 Bern, Switzerland
}

Corresponding author should be addressed to Sophie Baudat, Family and development research center, Institute of Psychology, University of Lausanne, Geopolis Building, 1015 Lausanne, Switzerland, sophie.baudat@unil.ch

This work was supported by grants from the Swiss National Science Foundation (SADYSM: ${ }^{\circ}$ 10001C_173418/1, and C-SURF: n 33C530_148493, 33CSC0-122679, and 33CS30-139467)

This article may not exactly replicate the final version published in the journal. The final version is in press in Drugs: Education, Prevention and Policy.

The exact reference is:

Baudat, S., Iglesias, K., Studer, S., Gmel, G., \& Baggio, S. (in press). Development of alcohol use disorder in young Swiss men: The influence of retrospectively perceived parenting profiles. Drugs: Education, Prevention and Policy. doi:10.1080/09687637.2020.1840514 


\begin{abstract}
This four-wave longitudinal study aimed to examine the associations between retrospectively perceived parenting profiles in adolescence and the development of alcohol use disorder (AUD) throughout emerging adulthood. The cohort consisted of 190 young Swiss men who completed retrospective reports of parenting at baseline and a short AUD self-report screening tool at four measurement times $($ mean age at baseline $=20.18$; Time 1: 21.52; Time 2: 25.61; Time 3: 26.99) . Latent profile analysis revealed three parenting profiles in adolescence based on retrospective measures of parenting styles and practices: Optimal (the highest levels of involvement, structure and knowledge; 69\%), Uninformed (high levels of involvement, moderate levels of structure and the lowest levels of knowledge; 17\%), Low Support (the lowest levels of involvement, moderate levels of structure and knowledge; 14\%). Using latent growth curve analysis, we found that young men in the Low Support profile experienced a greater increase in AUD severity compared with those in the Uninformed and Optimal profiles. Young men in the Uninformed profile reported higher levels of AUD severity at baseline than those in the Optimal profile. These findings highlight the associations between retrospectively perceived parenting profiles during adolescence and the development of AUD during emerging adulthood.
\end{abstract}

Keywords: alcohol use disorder, emerging adulthood, parenting, latent profile analysis, latent growth curve modeling 
Development of Alcohol Use Disorder in Young Swiss Men: The Influence of Retrospectively Perceived Parenting Profiles

\section{Introduction}

Emerging adulthood (18-29 years old) is considered as a distinct transitional period between adolescence and adulthood, characterized by exploration and change (Arnett, 2000; Schwartz, 2016). It is also a time of increased risk for alcohol use and disorder. For instance, according to the National Survey on Drug Use and Health conducted in the U.S. (Substance Abuse and Mental Health Services Administration, 2019), 34.9\% of young adults aged 18 to 25 reported binge drinking (i.e., four (for women)/five (for men) or more drinks on the same occasion) on at least one occasion in the past month. In addition, 9\% were current heavy alcohol drinkers (i.e., binge drinking on five or more times in the past month), and 10\% met DSM-5 criteria for alcohol use disorder (AUD) in the past year. In Switzerland, results from the Continuous Rolling Survey of Addictive Behaviors and Related Risks indicated that $38.2 \%$ of 20 to 24 -year-olds reported binge drinking at least once a month in the previous year (Gmel et al., 2017); 2.5\% had a probable disorder according to the AUDIT (Marmet et al., 2015). Moreover, alcohol use and drinking patterns (e.g., heavy drinking) are likely to increase throughout adolescence and early emerging adulthood, before declining from middle emerging adulthood to adulthood (Gates et al., 2016; Gmel et al., 2017; Schulenberg et al., 2019). Similarly, prevalence rates of AUD increase from adolescence to middle emerging adulthood (Palmer et al., 2009; Substance Abuse and Mental Health Services Administration, 2019; Teesson et al., 2010). To a certain extent, these changes reflect a developmental phenomenon as emerging adults are likely to experience a wide range of risky behaviors before endorsing adult responsibilities (Arnett, 2000; Sussman \& Arnett, 2014). Nevertheless, alcohol use among emerging adults has been associated with harmful consequences (e.g., Kuntsche et al., 2017; Marmet et al., 2014). Prevention of such impairment requires a better understanding of the risk and protective factors associated with the development of AUD among men during emerging adulthood (Sussman \& Arnett, 2014). Among noteworthy factors, the family context appears to play a key role in preventing alcohol use during 
emerging adulthood (for a review, see Stone et al., 2012). Indeed, although the transition to adulthood involves a move toward more independence from the family, scholars argued that parents remain an important resource by inhibiting or facilitating their child's movement toward individuation through socialization practices and styles (Aquilino \& Supple, 2001; Grotevant \& Cooper, 1986).

A first line of research based on the dimensional approach to parenting (Soenens et al., 2019) examined how various dimensions of parenting in the immediate family environment of young adults differentially influence their drinking behaviors. These parenting dimensions include, but are not limited to: involvement, which refers to the degree to which parents interact with their child in a warm and sensitive manner (Soenens et al., 2019); structure, which refers to parental attempts to regulate their child's behaviors, for instance through the communication of clear expectations and supervision (Soenens et al., 2019); and parental knowledge (also labeled "monitoring"), which refers to the extent to which parents are informed about their youth's leisure-time activities and peers (Kerr et al., 2010; Stattin \& Kerr, 2000) through dynamic communication with their disclosing child (Liu et al., 2020). In this research tradition, alcohol risk among young adults has thus been linked to the extent to which they perceived their parents as involved (e.g., Finan et al., 2018), structuring (e.g., Abar \& Turrisi, 2008; Cleveland et al., 2014) or knowledgeable (e.g., Padilla-Walker et al., 2008; Urry et al., 2011) during emerging adulthood.

This line of research has also examined the long-term effects of parenting styles and practices during adolescence on overall rates of alcohol use during emerging adulthood. Overall, the results suggest that parents exert their influence on the current behaviors of young adults through earlier aspects of parenting (Aquilino, 2006; Schwartz, 2016). Specifically, higher levels of perceived parental involvement in adolescence were longitudinally predictive of a lower likelihood of heavy episodic drinking (e.g., Plummer Lee et al., 2018), alcohol-related consequences (e.g., being drunk at school/work, driving under the influence of alcohol; Locke \& Newcomb, 2004; Schwartz et al., 2009), and DSM-IV AUD (e.g., Mak \& Iacovou, 2019) in emerging adulthood. Similarly, perceived parental structure in adolescence was consistently predictive of a reduced likelihood of drinking behaviors (e.g., number of drinks, binge drinking; Aquilino \& Supple, 2001; Roche et al., 2008) and 
DSM-IV AUD (e.g., Guo et al., 2001) during emerging adulthood. There is also some evidence showing that perceptions of parenting dimensions during adolescence predict specific trajectories of drinking behaviors from adolescence to early adulthood (e.g., Barnes et al., 2000; Chassin et al., 2002; Su et al., 2019).

Although the studies presented above are of great interest, they are limited to the distinct contribution of various dimensions of parenting on drinking behaviors among emerging adults. However, in the configurational approach of parenting (Baumrind, 1991; Maccoby \& Martin, 1983), parenting was initially conceptualized as a constellation involving a combination of styles and practices (Darling \& Steinberg, 1993). Therefore, the impact of parenting on alcohol use disorder in young adults needs to be understood and studied as the result of an interplay between the dimensions of parenting. This implies the use of an appropriate analytical approach to best capture how different combinations of multiple parenting styles and practices are related to outcomes in young adults (Abar et al., 2014). A second line of research based on the configurational approach therefore used a personcentered approach to identify the distinct profiles of parenting that characterize parent-young adult relationships, and examined their associations with overall rates of alcohol consumption. Specifically, using latent profile analysis, Mallett et al. (2011) identified links between profiles of parenting and later heavy drinking among college students, with authoritarian parenting profile being associated with increased risk for heavy drinking. Based on the same analytical approach, Abar (2012) found cross-sectional links between perceived parenting profiles and alcohol-related profiles among college students. Specifically, students in the high-quality parenting profile were more likely to be in the most optimal alcohol-related profiles; that is, profiles characterized by an absence or low levels of alcoholrelated characteristics (e.g., frequency of alcohol use, alcohol-related consequences and risky drinking behaviors). Profiles similar to those described by Abar (2012) were longitudinally associated with the likelihood of experiencing alcohol-related consequences one year later (Varvil-Weld et al., 2012), and with trajectories of change in drinking behaviors during the first year of college (Abar et al., 2014). Nevertheless, relatively little attention has been paid specifically to the extent to which the perceived parenting profiles in adolescence are related to the development of AUD in emerging adulthood. 


\section{The Present Study}

The main objective of the present longitudinal study was to examine the extent to which retrospectively perceived parenting profiles during adolescence are associated with the development of AUD as defined by DSM-5 among young men, using a short AUD self-report screening tool (Baggio et al., 2020). This definition, which combines alcohol dependence and alcohol abuse into a single disorder, allows for a better identification of less severe forms of AUD, resulting in higher prevalence for the DSM-5 than for the DSM-IV (Baggio et al., 2016). In addition, the criteria have changed with the inclusion of craving and the removal of alcohol abuse from the DSM-5 (Hasin et al., 2013). Based on previous studies (e.g., Abar et al., 2014; Varvil-Weld et al., 2012), we expected that growing up in a less optimal family environment (characterized by a combination of low levels of parental involvement, structure, and knowledge) during adolescence would be associated with higher levels of initial AUD and a greater increase in AUD scores during emerging adulthood.

\section{Method}

\section{Participants \& Procedure}

This four-wave longitudinal study is a secondary analysis of data collected in the Cohort Study Substance Use and Risk Factors (C-SURF; Gmel et al., 2015; Studer et al., 2013) and the study on Screening for Alcohol Dependence Among Young Swiss Men (SADYSM; Baggio et al., 2020; Iglesias et al., 2018). C-SURF is an ongoing longitudinal study examining the risk and protective factors associated with substance use among young Swiss men transitioning into adulthood. In order to have access to a broad and representative sample of the general population, participants were recruited at recruitment centers as 19 -year-old Swiss men have a mandatory 2-day military conscription. Three waves of questionnaires have already been collected since 2010: data collection at baseline took place between September 2010 and March 2012, follow-up 1 between March 2012 and January 2014, and follow-up 2 between April 2016 and March 2018. SADYSM is a related study that took place between October 2017 and April 2018 and tests the reliability of self-report measures of AUD with a subsample of the French-speaking C-SURF (Baggio et al., 2020; Iglesias et al., 2018). Specifically, participants enrolled in the third wave of C-SURF and who had a valid address e-mail ( $n$ 
$=2,668)$ were first invited in October 2017 to complete an online version of the Alcohol Use Disorder Identification Test (AUDIT; Saunders et al., 1993) ( $n=1,371,51.4 \%)$. Participants were then selected among two strata: those with a high AUDIT score $(\geq 13 ; n=193)$ and those with a low score $(<13 ; n$ $=1,178$, with a random selection of $n=137)$. Participants who agreed to be involved in the SADYSM study $(n=233,70.6 \%)$ attended a scheduled appointment at the University of Lausanne, during which they completed self-report measures of alcohol use. The final sample comprised participants $(n=190)$ who gave their consent to reuse their data collected as part of the C-SURF study and who completed the parenting questionnaires at baseline. For each of the four waves, the mean age was $20.18 \pm 1.43$, 21.52, 25.61 and 26.99, respectively. When comparing their family's financial situation with other families in Switzerland at baseline, $43.7 \%$ perceived their personal situation as average, $46.3 \%$ perceived it as above, and $10 \%$ perceived it as below. Of the participants, $89.4 \%$ were living with their parents at baseline, $69.8 \%$ at follow-up 1, and 38.9\% at follow-up 2. In terms of study status, $72.6 \%$ of the participants were studying at baseline, $55.8 \%$ at follow-up 1, and $65.8 \%$ at follow-up 2. With respect to their own financial situation, $23.7 \%$ of the participants reported being financially independent at baseline, $29.5 \%$ at follow-up 1 and $46.3 \%$ at follow-up 2.

Both studies were supported by grants from the Swiss National Science Foundation (SADYSM: $n^{\circ}$ 10001C_173418/1, and C-SURF: $n^{\circ}$ 33C530_148493, 33CSC0-122679, and 33CS30139467), and approved by the Ethic Committee of the Canton of Vaud ( $n^{\circ} 15 / 07$ and $\left.n^{\circ} 2017-00776\right)$. More detailed information about these studies can be found elsewhere (SADYSM: Baggio et al., 2020; Iglesias et al., 2018; C-SURF: Studer et al., 2013).

\section{Measures}

Alcohol use disorder (AUD). The individual DSM-5 AUD was assessed using a short selfreport screening tool (Baggio et al., 2020). This questionnaire combines eight symptoms of AUD (hazardous use, tolerance, withdrawal, unable to control/quit alcohol use, time spent getting/using/recovering alcohol, giving up other activities, having physical/psychological problems, and craving) and four alcohol-related consequences (doing things badly regretted after, accident/injury, unplanned sex, and conflict with authorities) within the previous 12 months. As 
recommended in Baggio et al. (2020), we assessed AUD as a continuous variable. For each wave, we computed scores by summing items assessing symptoms and alcohol-related consequences.

Compared with classical self-report measures of AUD, this screening tool has been shown to be a better alternative for capturing components of DSM-5 AUD, with good psychometric properties: sensitivity $=83.3 \%$, specificity $=78.7 \%$ (Baggio et al., 2020).

Parenting. In the first wave of C-SURF, participants completed retrospective self-report scales on parenting during adolescence. The use of retrospective reports among emerging adults is consistent with previous studies that have shown that retrospective perceptions of parenting styles are predictive of developmental and behavioral outcomes (e.g., alcohol use; Schwartz et al., 2009). This method also offers a more mature perspective on parenting, as emerging adults feel more free to reflect back on their parents' rearing style in its entirely (Finley \& Schwartz, 2010). In the present study, we focused on retrospective reports of three available dimensions of parenting: involvement, structure, and knowledge. Each dimension was assessed using two items adapted from the European School Survey Project on Alcohol and Other Drugs (ESPAD; Hibell et al., 2012). Given the diversity of family structures (Patterson et al., 2015), participants who grew up with foster parents, step-parents or other persons were explicitly asked to think of them when responding. Items of parental involvement examined the degree to which parent figures were perceived as warm, responsive, and loving ("I could easily get warmth and caring from my parents", "I could easily get emotional support from my parents"). Items of structure assessed the extent to which parent figures clearly communicated their expectations and rules about their child's behavior ("My parent(s) set definite rules about what I was allowed to do at home", "My parents set definite rules about what I was allowed to do outside home"). Finally, items of parental knowledge evaluated what parent figures actually knew about their child's whereabouts and companions during evenings ("My parents knew whom I was with in the evenings", "My parent(s) knew where I was in the evenings"). In line with the ESPAD (Hibell et al., 2012), participants were asked to think of their own family situation when they were approximately 15 years old and to respond on a 5-point Likert scale $(1=$ almost never, $5=$ almost always). A Confirmatory Factor Analysis was conducted to check the three-factor solution, in 
which the two items of involvement loaded on the first factor, the two items of structure on the second factor, and the two items of knowledge on the third factor. Results indicated that the three-factor model fit the data well, $\chi^{2}(6)=1.58, p<.954, \mathrm{CFI}=1.00, \mathrm{RMSEA}=.000,90 \% \mathrm{CI}[.000, .000]$, SRMR $=.009$, with factor loadings ranging between .78 and .98 . To ensure the reliability and divergent validity of the two-item factors, we examined the correlation matrix. As shown in Table 1, results provided evidence for reliable factors as items within each scale were highly correlated with one another. In addition, inter-items across factors were moderate to low and smaller in magnitude than convergent validity coefficients, suggesting that divergent validity exists between the three scales. Mean scores were computed for each dimension, with higher scores indicating higher levels of involvement, structure and knowledge, respectively.

\section{Plan of Analysis}

Statistical analyses were performed using R Statistical Software (R Core Team, 2018). First, in order to identify retrospectively perceived parenting profiles, we performed latent profile analyses (LPA) using the package "tidyLPA" (Rosenberg et al., 2018). A series of models were estimated using the set of retrospective measures of parental dimensions (i.e., involvement, structure and knowledge) as continuous indicators. To identify the model with the optimal number of profiles, we compared the following fit indices across solutions : (a) information criterion (i.e., Akaike Information Criteria [AIC], the Bayesian Information Criteria [BIC], and the sample-size adjusted BIC [SABIC]), with lower values on these statistics indicating better model fit (Berlin et al., 2014; Nylund et al., 2007); (b) p-value for the bootstrapped likelihood ratio test (BLRT) in order to examine whether there was a significant improvement in model fit with the inclusion of an additional profile (Nylund et al., 2007); (c) number of cases in each profile (no less than $1 \%$ of total count) (Jung \& Wickrama, 2008); (d) entropy, whose values approaching 1 indicate a clear delineation between profiles (Berlin et al., 2014; Celeux \& Soromenho, 1996). After classifying participants in their most likely profile membership, we also tested for mean differences in retrospectively perceived parenting dimensions between profiles. Statistically significant differences were used to characterize profiles. 
Second, in order to examine the long-term effect of parenting profiles on the development of AUD throughout emerging adulthood, we conducted latent growth curve modeling (Duncan et al., 2006; Preacher et al., 2008) using the package "lavaan" (Rosseel, 2012). Maximum likelihood estimation was used. Overall, $2.53 \%$ of the data was missing among repeated measures of AUD score and parenting profile. As Little's MCAR-test was not statistically significant $\chi^{2}(15)=20.87, p=.141$, missing data were dealt with a procedure of Full Information Maximum Likelihood. We first tested unconditional models to describe the overall trajectory of AUD throughout emerging adulthood. In line with Bollen and Curran (2006)'s recommendations, we tested linear and curvilinear (i.e., quadratic and cubic) models and compared them with a robust chi-square difference test (Satorra \& Bentler, 2001). The loadings on the linear slope factor were fixed at $0,1,4$ and 5 to represent unequal time intervals between the four assessments (i.e., 16.04 months between assessments 1 and 2, 49.14 months between assessments 2 and 3, and 16.5 months between assessments 3 and 4, respectively). Once the best fitting model has been selected, we tested a conditional model by dummy coding profile membership and including them as predictors of AUD growth factors. We assessed model fit using the comparative fit index (CFI), the root mean square error of approximation (RMSEA), and the standardized root mean square residual (SRMR). A CFI greater than .95, a RMSEA less than .06, and its associated $90 \%$ confidence intervals under 0.05 and 0.10, respectively, and a SRMR less than .08 are considered as evidence of good fit (Hu \& Bentler, 1999).

\section{Results}

Descriptive statistics and correlations among manifest variables are presented in Table 1.

\section{Latent Profiles of Parenting}

Using LPA, profiles were created using individuals' scores on a set of retrospective measures of parenting dimensions (i.e., involvement, structure, knowledge). We estimated and compared models with an incremental number of classes (i.e., 1 to 4). However, in the four-profile solution, some profiles were assigned to less than $1 \%$ of individuals, which suggested that this solution was identical to a solution with one profile less (Rosenberg et al., 2018). As shown in Table 2, the model with three profiles provided the best fit to the observed data. All information criteria (AIC, BIC, 
SABIC) were the lowest in the 3-profile solution. The significant $p$-value for BLRT indicated that the 3-profile model provided a significant better fit than the 2-profile model. The proportion of cases in each profile was sufficient (i.e., 14\%, 17\%, 69\%). Entropy for the three-profile solution was .83, which represents a high classification accuracy.

The means scores for the retrospective measures of the dimensions of parenting are detailed in Table 3. Results of a series of ANOVA with adjusted $p$-value (according to Benjamini-Hochberg's method) indicated that profiles significantly differ in terms of involvement, $F(1,188)=233.4, p<$ $.001, \eta^{2}=.55$, structure, $F(1,188)=38.83, p<.001, \eta^{2}=.17$, and knowledge, $F(1,188)=154, p<$ $.001, \eta^{2}=.45$. Post hoc comparisons using Tukey's test are presented in Table 3. The first profile (14\% of the sample) was labeled Low Support. Young men in this profile retrospectively reported the lowest scores on parental involvement and moderate levels of structure and knowledge. The main feature of this profile was low-quality parenting style in terms of warm and support. The second profile (17\%) was labeled Uninformed. Young men in this profile retrospectively reported high scores on involvement, moderate levels of structure, and the lowest scores on knowledge. In other words, a lack of communication characterized the parent-child relationship in this profile, with parents being retrospectively perceived as poorly informed about their adolescents' behavior. The third and last profile was labeled Optimal (69\%). Young men in this profile retrospectively reported the highest levels of involvement, structure and knowledge, which are generally considered characteristics of optimal parenting for youth development (e.g., Joussemet et al., 2014).

\section{Latent Growth Curve Models of AUD}

Using a latent growth curve modeling approach, we first examined how participants’ AUD change across emerging adulthood, without covariates. Specifically, we tested and compared linear and curvilinear (i.e. quadratic and cubic) growth models. According to the chi-square statistic, none of the nonlinear models significantly improved model fit, $\chi^{2}(4)=2.35, p=.671$ and $\chi^{2}(4)=2.76, p=$ .599 , respectively.

The unconditional linear growth model of AUD yielded an excellent fit, $\chi^{2}(5)=5.42, p=$ $.367, \mathrm{CFI}=.99, \mathrm{RMSEA}=.021,90 \% \mathrm{CI}[.000, .105], \mathrm{SRMR}=.033$. The mean slope of AUD was 
marginally significant $(p=.083)$, meaning that on average, there was almost no change in AUD across emerging adulthood (see Table 4). However, significant variability between individuals was observed on both the intercept and the slope, suggesting the presence of interindividual differences in the initial level and rate of change in AUD. Moreover, a significant negative covariance between the intercept and slope factors was found. This result indicates that the initial level of AUD was inversely related to the rate of change over time, suggesting a ceiling effect (Kaplan, 2009); that is, young men who initially scored high in AUD were less likely to increase in this variable over time.

Then, we tested conditional latent growth curve models with retrospectively perceived parenting profiles predicting AUD growth parameters. As we had three profiles, we dummy coded this variable, with Low Support being the reference group. In order to compare AUD growth factors of the Optimal and Uninformed profiles, we tested a second model with Optimal profile as the reference group. The $p$-values of the regression coefficients have thus been adjusted for multiple comparisons.

The conditional linear growth model of AUD yielded an excellent fit, $\chi^{2}(9)=13.62, p=.136$, $\mathrm{CFI}=.99, \mathrm{RMSEA}=.052,90 \% \mathrm{CI}[.000, .105], \mathrm{SRMR}=.035$. As shown in Table 4 and depicted in Figure 1, results showed that young men in the Uninformed profile reported higher levels of AUD at age 20 compared with those in the Low Support profile. This difference was, however, not statistically significant (adjusted $p=.136$ ), probably because of the relatively small sizes of the groups. Young men in the Optimal profile did not differ in terms of AUD at age 20 from those in the Low Support profile (adjusted $p>$.999). Furthermore, retrospectively perceived parenting profiles statistically significantly predicted the rate of change of AUD. This result suggests that young men in the Uninformed and Optimal profiles experienced less increase in AUD over time compared with those in the Low Support profile (adjusted $p=.004$ and $p=.018$ ).

Regarding the second model with the Optimal profile as the reference group, results indicated that young men in the Uninformed profile also reported higher levels of AUD at age 20 compared with those in the Optimal profile (adjusted $p=.030$ ). However, young men in the Uninformed profile did not differ in terms of rate of change in AUD than those in the Optimal profile (adjusted $p=.460$ ). 


\section{Discussion}

\section{Perceived Parenting Profiles in Adolescence}

Consistent with an integrative conceptualization of parenting (Darling \& Steinberg, 1993), LPA provided evidence for three distinct profiles characterized by different constellations of retrospective perceptions of parental involvement, structure, and knowledge. These profiles share similarities with the configurational approach of parenting (Baumrind, 1991; Maccoby \& Martin, 1983). Specifically, more than two thirds of our sample, who were assigned to the Optimal parenting profile, retrospectively perceived their parent figures as highly supportive, structuring, and knowledgeable during their adolescence; thereby overlapping some characteristics of Baumrind (1991)'s authoritative parenting style (i.e., low involvement and high structure). These parental dimensions are likely to be considered as important indicators of an optimal parenting for the development of young people (Soenens et al., 2019), which means that the majority of young men in our sample retrospectively perceived a positive parenting style during adolescence. This finding adds to the already widespread evidence that, despite changing patterns of interaction between parents and adolescents, a rejective, unpredictable and lenient parenting only concerns a minority of families during adolescence (Smetana et al., 2006; Steinberg, 2001).

The fact remains that an important proportion of young men retrospectively perceived poor parenting in its entirely during adolescence. Specifically, young men in the Low Support profile retrospectively reported the lowest levels of parental involvement during adolescence, along with moderate levels of structure and knowledge. This profile shares characteristics of structure and involvement of the authoritarian parenting style described by Baumrind (1991). Indeed, the latter refers to parents who are highly regulating their offspring behaviors, for instance through the communication of rules and supervision, while interacting with them in a low supportive and sensitive manner. In addition, the Uninformed profile overlaps some components of Baumrind (1991)'s permissive parenting style, as it describes parent figures who were highly supportive and moderately structuring. It is also important to note that young men in the Uninformed profile differed from those in the two other profiles, in particular regarding the extent to which they perceived their parent figures 
as being knowledgeable of their whereabouts and friends. Parental knowledge mainly stems from the communication dynamics between parents and children; that is, from the child's willingness to disclose information and, to a lesser extent, from parents' active efforts to gain insight into their child's unsupervised activities (Kerr et al., 2010; Liu et al., 2020). By extension, we could hypothesize that the young men in the Uninformed profile perceived in retrospect that they grew up in a relatively lenient parenting context in which they barely communicated with their parent figures about their unsupervised activities.

\section{Parenting Profiles as Predictors of AUD Trajectories in Emerging Adulthood}

Consistent with previous studies (e.g., Abar et al., 2014; Mallett et al., 2011), the results of latent growth curve modeling indicate that retrospectively perceived parenting profiles in adolescence accounted for some of the variability in AUD trajectories among young men. Specifically, young men in the Low Support profile did not statistically significantly differ from those in the Optimal profiles in terms of AUD at early emerging adulthood. However, they were more likely to report lower levels of AUD at age 20 than those in the Uninformed profile, although the difference was not statistically significant, probably due to a lack of power. Additionally, young men in the Low Support profile experienced a greater increase in AUD over time compared with those in the Uninformed profile. Interestingly, this finding suggests that young men who, in retrospect, perceived their parent figures as less involved during adolescence are less likely to suffer from AUD in early adulthood, compared with young men who perceived their parent figures as less knowledgeable. However, they would be more likely to develop AUD severity throughout their transition to adulthood. In other words, retrospective perception of a lack of parental knowledge (Uninformed profile) appears to have implications for the severity of AUD in early emerging adulthood, while retrospective perception of an unsupportive parenting style (Low Support profile) appears to have more impact later in life. Hence, even combined with moderate levels of structure and knowledge, which are considered as protective factors (e.g., Guo et al., 2001; e.g., Padilla-Walker et al., 2008), retrospective perceptions of a lack of parental involvement is a major contextual risk factor of developing AUD later in emerging adulthood. In line with previous research (Mak \& Iacovou, 2019; Su et al., 2019), this new 
finding here supports the idea that young men benefit from a parenting style which strengthened the development of their capacity for agency and healthy decision-making (Kogan, 2017).

Another important finding is that young men in the Uninformed profile differed from those in the Optimal profile in AUD trajectories. Specifically, they reported greater AUD severity at early emerging adulthood, which is consistent with previous studies showing that low parental knowledge is associated with a higher risk for drinking behaviors (e.g., Padilla-Walker et al., 2008). Our results also showed small and non-significant differences between these two profiles in terms of change in AUD over time. Overall, young men who retrospectively perceive their parents as uninformed about their activities and friends during adolescence would be more likely to suffer from AUD before they begin the transition into adulthood, compared with those who perceive their parents as highly supportive and structuring. Furthermore, from a long-term perspective, young men in the Uninformed profile only slightly decrease in AUD severity during emerging adulthood. This is consistent with past studies showing that adolescents who reported a lack of communication with their parents are prone to be involved in alcohol use at early age and to increase rapidly to higher levels of drinking across adolescence (Koning et al., 2012).

\section{Implications for Parental Figures and Prevention}

Although peer influences increase during the transition to adulthood (White \& Jackson, 2004), the present study adds to the literature that highlights the central role of parent figures in preventing substance use among young men through socialization practices and styles (Aquilino, 2006; Schwartz, 2016). The results of this study therefore provide parent figures with some indication of protective rearing styles against risky drinking behaviors. Specifically, a parent-adolescent relationship characterized by a high level of involvement of parent figures appears to be an effective parenting style that may prevent the further development of AUD. Young men could thus benefit in the long-term from parent figures retrospectively perceived as warm, attentive, and sensitive. In addition, successful parenting involves structuring the child's behavior, as long as the parent figures set clear rules and expectations in a supportive parenting context. Indeed, previous studies stated that the style of communication used by parents and the context within which they convey regulations and 
expectations are crucial to foster the acceptance and the internalization of these rules by children (Van Petegem et al., 2017). In turn, internalized rules are associated with less externalizing problems (Brenning et al., 2019). Finally, in line with this point, dynamics of communication also have implications for the development of AUD among young men. When parent figures are sufficiently knowledgeable of their offspring's leisure time, through their child's disclosure or their own practices (e.g., asking a question), they are given the ability to shape their children's decisions and behaviors, and to assist them when they are at potential risks (Marshall et al., 2005).

As young men and their families sometimes need external and professional help in order to develop and strengthen optimal patterns of interaction, family-based interventions could focus on deficient aspect of the relationship, including a lack of involvement, structure, or communication. Previous studies demonstrated the long-term effectiveness of such family-centered interventions in reducing drinking behaviors among adolescents (for a review, see Velleman et al., 2005) and emerging adults (e.g., Stormshak et al., 2018). Family-centered interventions could also be useful for families with emerging adult children. Indeed, although family-centered interventions targeting parent-emerging adult relationships are still limited (Schwartz \& Petrova, 2019), recent studies examining their effectiveness show promising results (e.g., Stormshak et al., 2019).

\section{Limitations and Future Directions}

Although this study complements the existing literature by showing the contribution of retrospectively perceived profiles of parenting in adolescence on the development of AUD among young men, a number of limitations should be considered. First, statistical analyses were conducted with a subsample from the ongoing C-SURF study to allow the use of a fourth measurement point available in the SADYSM study. Due to the relatively small sample size used for latent profile analyses $(N=190)$, the number of profiles was quickly reduced, meaning that only a certain number of profiles could have been identified. Results should be extended to the entire sample of the ongoing C-SURF study in order to confirm the number of parenting profiles obtained or examine whether others emerged, as well as to reduce the lack of power encountered in longitudinal analyses. Second, with respect to our measures, it should be recognized that although the AUD screening tool is a good 
alternative for capturing the components of the DSM-5 AUD, it is still a self-report measure. In addition, the retrospective measures of parenting focused on three broad dimensions and consisted of a limited number of items. Moreover, although parents contribute differentially to the development of their offspring (Jeynes, 2016; Schoppe-Sullivan \& Fagan, 2020), our participants were asked to report on their parent figures' style and practices, without differentiating between the rearing style of each of them (e.g., mother and father). Furthermore, although literature has provided evidence for parentadolescent discrepancies in their perceptions of parenting style that may affect adolescent adjustment (e.g., De Los Reyes et al., 2019), the findings from the present study uniquely rely on young men's perceptions of parenting. Future work would therefore benefit from including alcohol-specific parenting (e.g., parental permissiveness toward alcohol use; Mallett et al., 2019); from considering the role of autonomy-supportive (vs. controlling) context and the style of communication of structure (Baudat et al., 2017; Van Petegem et al., 2017); and from identifying patterns of parenting based on assessments for each person who plays an important educational role (e.g., step-parent, foster-parent, grandparent) from multi-informant sources. Third, as not only the parenting style adopted by parents but also its effects are likely to vary according to the broader social and economic context (Doepke \& Zilibotti, 2019; Ulferts, 2020), future research could also control for the potential influence of socioeconomic factors. Finally, even if between-individual variance was accounted for in our study, previous studies provided evidence for multiple trajectories of drinking behaviors during the transition to adulthood (Chassin et al., 2002; Greenbaum et al., 2005). Another potential direction for future work would thus to use growth mixture modeling among larger samples in order to examine links between profiles of parenting in adolescence and multiple trajectories of AUD among young men.

\section{Conclusion}

Overall, the present study underscores the importance of examining the associations between retrospectively perceived parenting and AUD among young men by looking at patterns of styles and practices, rather than the individual influence of specific parental dimensions. Consistent with previous studies, the proximal influence of the family on the development of AUD among young men varies with the constellation of parental dimensions: a supportive parenting context appears the most 
effective when it coincides with rules and limits and a good communication between parents and adolescents. 
Disclosure of interest. The authors report no conflict of interest. 
References

Abar, C. C. (2012). Examining the relationship between parenting types and patterns of student alcohol-related behavior during the transition to college. Psychology of Addictive Behaviors, 26(1), 20-29. https://doi.org/10.1037/a0025108

Abar, C. C., \& Turrisi, R. J. (2008). How important are parents during the college years? A longitudinal perspective of indirect influences parents yield on their college teens' alcohol use. Addict Behav, 33(10), 1360-1368. https://doi.org/10.1016/j.addbeh.2008.06.010

Abar, C. C., Turrisi, R. J., \& Mallett, K. A. (2014). Differential trajectories of alcohol-related behaviors across the first year of college by parenting profiles. Psychology of Addictive Behaviors, 28(1), 53-61. https://doi.org/10.1037/a0032731

Aquilino, W. S. (2006). Family relationships and support systems in emerging adulthood. In J. J. Arnett \& J. L. Tanner (Eds.), Emerging adults in America: Coming of age in the 21 st century. (pp. 193-217). American Psychological Association. https://doi.org/10.1037/11381-008

Aquilino, W. S., \& Supple, A. J. (2001). Long-term effects of parenting practices during adolescence on well-being outcomes in young adulthood. Journal of Family Issues, 22(3), 289-308. https://doi.org/10.1177/019251301022003002

Arnett, J. J. (2000). Emerging adulthood: A theory of development from the late teens through the twenties. American Psychologist, 55(5), 469-480. https://doi.org/10.1037/0003066X.55.5.469

Baggio, S., Studer, J., Dupuis, M., \& Gerhard, G. (2016). Subthreshold problem drinkers in DSM-5 alcohol use disorder classification. The American journal on addictions, 25(5), 408-415. https://doi.org/10.1111/ajad.12404

Baggio, S., Trächsel, B., Rousson, V., Rothen, S., Studer, J., Marmet, S., Heller, P., Sporkert, F., Daeppen, J.-B., Gmel, G., \& Iglesias, K. (2020). Identifying an accurate self-reported screening tool for alcohol use disorder: evidence from a Swiss, male population-based assessment. Addiction, 115, 426-436. https://doi.org/10.1111/add.14864

Barnes, G. M., Reifman, A. S., Farrell, M. P., \& Dintcheff, B. A. (2000). The effects ofparenting on the development of adolescent alcohol misuse: A six-wave latent growth model. Journal of Marriage and Family, 62(1), 175-186. https://doi.org/10.1111/j.1741-3737.2000.00175.x

Baudat, S., Zimmermann, G., Antonietti, J.-P., \& Van Petegem, S. (2017). The role of maternal communication style in adolescents' motivation to change alcohol use: A vignette-based study. Drugs: Education, Prevention and Policy, 24(2), 152-162. https://doi.org/10.1080/09687637.2016.1192584

Baumrind, D. (1991). The influence of parenting style on adolescent competence and substance use. The Journal of Early Adolescence, 11(1), 56-95. https://doi.org/10.1177/0272431691111004

Berlin, K. S., Williams, N. A., \& Parra, G. R. (2014). An introduction to latent variable mixture modeling (part 1): Overview and cross-sectional latent class and latent profile analyses. Journal of Pediatric Psychology, 39(2), 174-187. https://doi.org/10.1093/jpepsy/jst084

Bollen, K. A., \& Curran, P. J. (2006). Latent curve models: A structural equation perspective. Wiley.

Brenning, K. M., Antrop, I., Van Petegem, S., Soenens, B., De Meulenaere, J., Rodríguez-Meirinhos, A., \& Vansteenkiste, M. (2019). I won't obey!: Psychologically controlling parenting and (non)-clinical adolescents' responses to rule-setting. Journal of Clinical Psychology, 75(6), 1034-1046. https://doi.org/10.1002/jclp.22750

Celeux, G., \& Soromenho, G. (1996). An entropy criterion for assessing the number of clusters in a mixture model. Journal of Classification, 13(2), 195-212. https://doi.org/10.1007/BF01246098

Chassin, L., Pitts, S. C., \& Prost, J. (2002). Binge drinking trajectories from adolescence to emerging adulthood in a high-risk sample: Predictors and substance abuse outcomes. Journal of Consulting and Clinical Psychology, 70(1), 67-78. https://doi.org/10.1037/0022-006x.70.1.67

Cleveland, M. J., Reavy, R., Mallett, K. A., Turrisi, R., \& White, H. R. (2014). Moderating effects of positive parenting and maternal alcohol use on emerging adults' alcohol use: Does living at home matter? Addict Behav, 39(5), 869-878. https://doi.org/10.1016/j.addbeh.2014.01.028 
Darling, N., \& Steinberg, L. (1993). Parenting style as context: An integrative model. Psychological Bulletin, 113(3), 487-496. https://doi.org/10.1037/0033-2909.113.3.487

De Los Reyes, A., Ohannessian, C. M., \& Racz, S. J. (2019). Discrepancies between adolescent and parent reports about family relationships. Child Development Perspectives, 13(1), 53-58. https://doi.org/10.1111/cdep.12306

Doepke, M., \& Zilibotti, F. (2019). Love, money, and parenting: How economics explains the way we raise our kids. Princeton University Press. https://doi.org/10.2307/j.ctvc77fr1

Duncan, T. E., Duncan, S. C., \& Strycker, L. A. (2006). An introduction to latent variable growth curve modeling: Concept, issues and applications (2nd ed.). Lawrence Erlbaum.

Finan, L. J., Simpson, E., Schulz, J., \& McCauley Ohannessian, C. (2018). Parental problem drinking and emerging adult problem behavior: The moderating role of parental support. Journal of Child and Family Studies, 27(4), 1175-1185. https://doi.org/10.1007/s10826-017-0953-8

Finley, G. E., \& Schwartz, S. J. (2010). The divided world of the child: Divorce and long-term psychosocial adjustment. Family Court Review, 48(3), 516-527. https://doi.org/10.1111/j.1744-1617.2010.01326.x

Gates, J. R., Corbin, W. R., \& Fromme, K. (2016). Emerging adult identity development, alcohol use, and alcohol-related problems during the transition out of college. Psychology of addictive behaviors: Journal of the Society of Psychologists in Addictive Behaviors, 30(3), 345-355. https://doi.org/10.1037/adb0000179

Gmel, G., Akre, C., Astudillo, M., Bähler, C., Baggio, S., Bertholet, N., Clair, C., Cornuz, J., Daeppen, J.-B., Deline, S., Dermota, P., Dey, M., Dupuis, M., Estévez, N., Foster, S., Gaume, J., Haug, S., Henchoz, Y., Kuendig, H., Mohler-Kuo, M., N'Goran, A., Schaub, M., Studer, J., Suris, J.-C., \& Wang, J. (2015). The Swiss Cohort Study on Substance Use Risk Factors Findings of two waves. Sucht: Zeitschrift für Wissenschaft und Praxis, 61(4), 251-262. https://doi.org/10.1024/0939-5911.a000380

Gmel, G., Kuendig, H., Notari, L., \& Gmel, C. (2017). Monitorage suisse des addictions : Consommation d'alcool, tabac et drogues illégales en Suisse en 2016 [Addiction Monitoring in Switzerland: Alcohol, tobacco and illicit drug use in Switzerland in 2016]. Addiction Switzerland.

Greenbaum, P. E., Del Boca, F. K., Darkes, J., Wang, C.-P., \& Goldman, M. S. (2005). Variation in the drinking trajectories of freshmen college students. Journal of Consulting and Clinical Psychology, 73(2), 229-238. https://doi.org/10.1037/0022-006X.73.2.229

Grotevant, H., \& Cooper, C. (1986). Individuation in Family Relationships. Human Development, 29, 82-100. https://doi.org/10.1159/000273025

Guo, J., Hawkins, J. D., Hill, K. G., \& Abbott, R. D. (2001). Childhood and adolescent predictors of alcohol abuse and dependence in young adulthood. Journal of Studies on Alcohol, 62(6), 754762. https://doi.org/10.15288/jsa.2001.62.754

Hasin, D. S., O'Brien, C. P., Auriacombe, M., Borges, G., Bucholz, K., Budney, A., Compton, W. M., Crowley, T., Ling, W., Petry, N. M., Schuckit, M., \& Grant, B. F. (2013). DSM-5 criteria for substance use disorders: Recommendations and rationale. Am J Psychiatry, 170(8), 834-851. https://doi.org/10.1176/appi.ajp.2013.12060782

Hibell, B., Guttormsson, U., Ahlstrom, S., Balakireva, O., Bjarnason, T., Kokkevi, A., \& Kraus, L. (2012). The 2011 ESPAD report: Substance use among students in 36 European countries. The Swedish Council for Information on Alcohol and Other Drugs (CAN).

Hu, L.-t., \& Bentler, P. M. (1999). Cutoff criteria for fit indexes in covariance structure analysis: Conventional criteria versus new alternatives. Structural Equation Modeling: A Multidisciplinary Journal, 6(1), 1-55. https://doi.org/10.1080/10705519909540118

Iglesias, K., Sporkert, F., Daeppen, J.-B., Gmel, G., \& Baggio, S. (2018). Comparison of self-reported measures of alcohol-related dependence among young Swiss men: a study protocol for a cross-sectional controlled sample. BMJ Open, 8(7), e023632. https://doi.org/10.1136/bmjopen-2018-023632

Jeynes, W. H. (2016). Meta-analysis on the roles of fathers in parenting: Are they unique? Marriage \& Family Review, 52(7), 665-688. https://doi.org/10.1080/01494929.2016.1157121 
Joussemet, M., Mageau, G. A., \& Koestner, R. (2014). Promoting optimal parenting and children's mental health: A preliminary evaluation of the how-to parenting program. Journal of Child and Family Studies, 23(6), 949-964. https://doi.org/10.1007/s10826-013-9751-0

Jung, T., \& Wickrama, K. A. S. (2008). An introduction to latent class growth analysis and growth mixture modeling. Social and Personality Psychology Compass, 2(1), 302-317. https://doi.org/10.1111/j.1751-9004.2007.00054.x

Kaplan, D. (2009). Structural equation modeling: Foundations and extensions (2nd ed.). SAGE Publications. https://doi.org/10.4135/9781452226576

Kerr, M., Stattin, H., \& Burk, W. J. (2010). A reinterpretation of parental monitoring in longitudinal perspective. Journal of Research on Adolescence, 20(1), 39-64. https://doi.org/10.1111/j.1532-7795.2009.00623.x

Kogan, S. M. (2017). The role of parents and families in preventing young adult alcohol use. Journal of Adolescent Health, 61(2), 127-128. https://doi.org/10.1016/j.jadohealth.2017.05.019

Koning, I. M., van den Eijnden, R. J. J. M., Verdurmen, J. E. E., Engels, R. C. M. E., \& Vollebergh, W. A. M. (2012). Developmental alcohol-specific parenting profiles in adolescence and their relationships with adolescents' alcohol use. Journal of Youth and Adolescence, 41(11), 15021511. https://doi.org/10.1007/s10964-012-9772-9

Kuntsche, E., Kuntsche, S., Thrul, J., \& Gmel, G. (2017). Binge drinking: Health impact, prevalence, correlates and interventions. Psychology and Health, 32(8), 976-1017. https://doi.org/10.1080/08870446.2017.1325889

Liu, D., Chen, D., \& Brown, B. B. (2020). Do parenting practices and child disclosure predict parental knowledge? A meta-analysis. Journal of Youth and Adolescence, 49(1), 1-16. https://doi.org/10.1007/s10964-019-01154-4

Locke, T. F., \& Newcomb, M. D. (2004). Adolescent predictors of young adult and adult alcohol involvement and dysphoria in a prospective community sample of women. Prevention Science, 5(3), 151-168. https://doi.org/10.1023/B:PREV.0000037639.78352.3c

Maccoby, E. E., \& Martin, J. A. (1983). Socialization in the context of the family: Parent-child interaction. In P. H. Mussen \& E. M. Hetherington (Eds.), Handbook of child psychology (4ème ed., Vol. 4, pp. 1-101). Wiley.

Mak, H. W., \& Iacovou, M. (2019). Dimensions of the parent-child relationship: Effects on substance use in adolescence and adulthood. Substance Use \& Misuse, 54(5), 724-736. https://doi.org/10.1080/10826084.2018.1536718

Mallett, K. A., Turrisi, R., Ray, A. E., Stapleton, J., Abar, C., Mastroleo, N. R., Tollison, S., Grossbard, J., \& Larimer, M. E. (2011). Do parents know best? Examining the relationship between parenting profiles, prevention efforts, and peak drinking in college students. Journal of Applied Social Psychology, 41(12), 2904-2927. https://doi.org/10.1111/j.15591816.2011.00860.x

Mallett, K. A., Turrisi, R., Reavy, R., Russell, M., Cleveland, M. J., Hultgren, B., Larimer, M. E., Geisner, I. M., \& Hospital, M. (2019). An examination of parental permissiveness of alcohol use and monitoring, and their association with emerging adult drinking outcomes across college. Alcoholism: Clinical and Experimental Research, 43(4), 758-766. https://doi.org/10.1111/acer.13978

Marmet, S., Notari, L., \& Gmel, G. (2015). Suchtmonitoring Schweiz-Screening für problematischen Alkoholkonsum im Jahr 2015. Addiction Suisse.

Marmet, S., Rehm, J., Gmel, G., Frick, H., \& Gmel, G. (2014). Alcohol-attributable mortality in Switzerland in 2011 - Age-specific causes of death and impact of heavy versus non-heavy drinking. Swiss Medical Weekly, 144, w13947. https://doi.org/10.4414/smw.2014.13947

Marshall, S. K., Tilton-Weaver, L. C., \& Bosdet, L. (2005). Information management: Considering adolescents' regulation of parental knowledge. Journal of Adolescence, 28(5), 633-647. https://doi.org/10.1016/j.adolescence.2005.08.008

Nylund, K. L., Asparouhov, T., \& Muthén, B. O. (2007). Deciding on the number of classes in latent class analysis and growth mixture modeling: A monte carlo simulation study. Structural Equation Modeling: A Multidisciplinary Journal, 14(4), 535-569. https://doi.org/10.1080/10705510701575396 
Padilla-Walker, L. M., Nelson, L. J., Madsen, S. D., \& Barry, C. M. (2008). The role of perceived parental knowledge on emerging adults' risk behaviors. Journal of Youth and Adolescence, 37(7), 847-859. https://doi.org/10.1007/s10964-007-9268-1

Palmer, R. H., Young, S. E., Hopfer, C. J., Corley, R. P., Stallings, M. C., Crowley, T. J., \& Hewitt, J. K. (2009). Developmental epidemiology of drug use and abuse in adolescence and young adulthood: Evidence of generalized risk. Drug Alcohol Depend, 102(1-3), 78-87. https://doi.org/10.1016/j.drugalcdep.2009.01.012

Patterson, C. J., Farr, R. H., \& Hastings, P. D. (2015). Socialization in the context of family diversity. In J. E. Grusec \& P. D. Hastings (Eds.), Handbook of socialization: Theory and research (pp. 202-227). The Guilford Press.

Plummer Lee, C., Beckert, T., \& Marsee, I. (2018). Well-being and substance use in emerging adulthood: The role of individual and family factors in childhood and adolescence. Journal of Child and Family Studies, 27(12), 3853-3865. https://doi.org/10.1007/s10826-018-1227-9

Preacher, K. J., Wichman, A. L., MacCallum, R. C., \& Briggs, N. E. (2008). Latent growth curve modeling. Sage.

R Core Team. (2018). R: A language and environment for statistical computing. R Foundation for Statistical Computing. https://www.R-project.org/

Roche, K. M., Ahmed, S., \& Blum, R. W. (2008). Enduring consequences of parenting for risk behaviors from adolescence into early adulthood. Social Science \& Medicine, 66(9), 20232034. https://doi.org/10.1016/j.socscimed.2008.01.009

Rosenberg, J., Beymer, P., Anderson, D. J., \& Schmidt, J. (2018). tidyLPA: An R package to easily carry out latent profile analysis (LPA) using open-source or commercial software. Journal of Open Source Software, 3, 978. https://doi.org/10.21105/joss.00978

Rosseel, Y. (2012). lavaan: An R Package for Structural Equation Modeling. Journal of Statistical Software, 48(2), 36. https://doi.org/10.18637/jss.v048.i02

Satorra, A., \& Bentler, P. M. (2001). A scaled difference chi-square test statistic for moment structure analysis. Psychometrika, 66(4), 507-514. https://doi.org/10.1007/BF02296192

Saunders, J. B., Aasland, O. G., Babor, T. F., de la Fuente, J. R., \& Grant, M. (1993). Development of the Alcohol Use Disorders Identification Test (AUDIT): WHO Collaborative Project on Early Detection of Persons with Harmful Alcohol Consumption--II. Addiction, 88(6), 791-804. https://doi.org/10.1111/j.1360-0443.1993.tb02093.x

Schoppe-Sullivan, S. J., \& Fagan, J. (2020). The evolution of fathering research in the 21st century: Persistent challenges, new directions. Journal of Marriage and Family, 82(1), 175-197. https://doi.org/10.1111/jomf.12645

Schulenberg, J. E., Johnston, L. D., O’Malley, P. M., Bachman, J. G., Miech, R. A., \& Patrick, M. E. (2019). Monitoring the Future national survey results on drug use, 1975-2018: Volume II, College students and adults ages 19-60. Institute for Social Research, University of Michigan.

Schwartz, S. J. (2016). Turning point for a turning point: Advancing emerging adulthood theory and research. Emerging Adulthood, 4(5), 307-317. https://doi.org/10.1177/2167696815624640

Schwartz, S. J., \& Petrova, M. (2019). Prevention science in emerging adulthood: A field coming of age. Prevention Science, 20(3), 305-309. https://doi.org/10.1007/s11121-019-0975-0

Schwartz, S. J., Zamboanga, B. L., Ravert, R. D., Kim, S. Y., Weisskirch, R. S., Williams, M. K., Bersamin, M., \& Finley, G. E. (2009). Perceived parental relationships and health-risk behaviors in college-attending emerging adults. Journal of Marriage and Family, 71(3), 727740. https://doi.org/10.1111/j.1741-3737.2009.00629.x

Smetana, J. G., Campione-Barr, N., \& Metzger, A. (2006). Adolescent development in interpersonal and societal contexts. Annual Review of Psychology, 57, 255-284. https://doi.org/10.1146/annurev.psych.57.102904.190124

Soenens, B., Vansteenkiste, M., \& Beyers, W. (2019). Parenting adolescents. In M. H. Bornstein (Ed.), Handbook of parenting : vol.1 : children and parenting (Vol. 1, pp. 101-167). Routledge.

Stattin, H., \& Kerr, M. (2000). Parental monitoring: A reinterpretation. Child Development, 71(4), 1072-1085. https://doi.org/10.1111/j.1532-7795.2009.00623.x 
Steinberg, L. (2001). We know some things: Parent-adolescent relationships in retrospect and prospect. Journal of Research on Adolescence, 11(1), 1-19. https://doi.org/10.1111/15327795.00001

Stone, A. L., Becker, L. G., Huber, A. M., \& Catalano, R. F. (2012). Review of risk and protective factors of substance use and problem use in emerging adulthood. Addict Behav, 37(7), 747775. https://doi.org/10.1016/j.addbeh.2012.02.014

Stormshak, E. A., Caruthers, A., Chronister, K., DeGarmo, D., Stapleton, J., Falkenstein, C., DeVargas, E., \& Nash, W. (2019). Reducing risk behavior with family-centered prevention during the young adult years. Prevention Science, 20(3), 321-330. https://doi.org/10.1007/s11121-018-0917-2

Stormshak, E. A., DeGarmo, D., Chronister, K., \& Caruthers, A. (2018). The impact of familycentered prevention on self-regulation and subsequent long-term risk in emerging adults. Prevention Science, 19(4), 549-558. https://doi.org/10.1007/s11121-017-0852-7

Studer, J., Baggio, S., Mohler-Kuo, M., Dermota, P., Gaume, J., Bertholet, N., Daeppen, J.-B., \& Gmel, G. (2013). Examining non-response bias in substance use research-Are late respondents proxies for non-respondents? Drug and Alcohol Dependence, 132(1), 316-323. https://doi.org/10.1016/j.drugalcdep.2013.02.029

Su, J., Supple, A. J., Leerkes, E. M., \& Kuo, S. I. C. (2019). Latent trajectories of alcohol use from early adolescence to young adulthood: Interaction effects between 5-HTTLPR and parenting quality and gender differences. Development and Psychopathology, 31(2), 457-469. https://doi.org/10.1017/S095457941800024X

Substance Abuse and Mental Health Services Administration, S. (2019). Key substance use and mental health indicators in the United States: Results from the 2018 National Survey on Drug Use and Health. Center for Behavioral Health Statistics and Quality, Substance Abuse and Mental Health Services Administration.

Sussman, S., \& Arnett, J. J. (2014). Emerging adulthood: Developmental period facilitative of the dddictions. Evaluation and the Health Professions, 37(2), 147-155. https://doi.org/10.1177/0163278714521812

Teesson, M., Hall, W., Slade, T., Mills, K., Grove, R., Mewton, L., Baillie, A., \& Haber, P. (2010). Prevalence and correlates of DSM-IV alcohol abuse and dependence in Australia: Findings of the 2007 National Survey of Mental Health and Wellbeing. Addiction, 105(12), 2085-2094. https://doi.org/10.1111/j.1360-0443.2010.03096.x

Ulferts, H. (2020). Why parenting matters for children in the 21 st century. An evidence-based framework for understanding parenting and its impact on child development. OECD Publishing. https://doi.org/10.1787/129a1a59-en

Urry, S. A., Nelson, L. J., \& Padilla-Walker, L. M. (2011). Mother knows best: Psychological control, child disclosure, and maternal knowledge in emerging adulthood. Journal of Family Studies, 17(2), 157-173. https://doi.org/10.5172/jfs.2011.17.2.157

Van Petegem, S., Zimmer-Gembeck, M. J., Soenens, B., Vansteenkiste, M., Brenning, K., Mabbe, E., Vanhalst, J., \& Zimmermann, G. (2017). Does general parenting context modify adolescents' appraisals and coping with a situation of parental regulation ? The case of autonomysupportive parenting. Journal of Child and Family Studies, 26(2), 2623-2639. https://doi.org/10.1007/s10826-017-0758-9

Varvil-Weld, L., Mallett, K. A., Turrisi, R., \& Abar, C. C. (2012). Using parental profiles to predict membership in a subset of college students experiencing excessive alcohol consequences: Findings from a longitudinal study. Journal of Studies on Alcohol and Drugs, 73(3), 434-443. https://doi.org/10.15288/jsad.2012.73.434

Velleman, R. D. B., Templeton, L. J., \& Copello, A. G. (2005). The role of the family in preventing and intervening with substance use and misuse: A comprehensive review of family interventions, with a focus on young people. Drug and Alcohol Review, 24(2), 93-109. https://doi.org/10.1080/09595230500167478

White, H. R., \& Jackson, K. (2004). Social and psychological influences on emerging adult drinking behavior. Alcohol Research \& Health, 28(4), 182-190. 
Table 1

Correlation matrix of items measuring parenting dimensions $(\mathrm{N}=190)$

\begin{tabular}{|c|c|c|c|c|c|}
\hline & Involvement1 & Involvement 2 & Structure1 & Structure2 & Knowledge1 \\
\hline Involvement1 & - & & & & \\
\hline Involvement 2 & $.81^{* * * *}$ & - & & & \\
\hline Structure1 & $.34^{* * * *}$ & $.26^{* * * *}$ & - & & \\
\hline Structure2 & $.39^{* * *}$ & $.32^{* * * *}$ & $.74^{* * *}$ & - & \\
\hline Knowledge1 & $.34^{* * * *}$ & $.29^{* * * *}$ & $.25^{* * *}$ & $.33^{* * *}$ & - \\
\hline Knowledge2 & $.42^{* * * *}$ & $.38^{* * *}$ & $.29^{* * *}$ & $.38^{* * *}$ & $.77^{* * *}$ \\
\hline
\end{tabular}

${ }^{*} p<.05 .{ }^{* *} p<.01 .{ }^{* * *} p<.001$ 
Table 2

Descriptive Statistics and Correlations of Manifest Variables $(\mathrm{N}=190)$

\begin{tabular}{|c|c|c|c|c|c|c|c|c|c|c|}
\hline & $n$ & $M(\mathrm{SD})$ & Range & 1 & 2 & 3 & 4 & 5 & 6 & 7 \\
\hline 1. BL self-report AUD & 178 & $2.33(2.31)$ & $0-12$ & - & $.72^{* * * *}$ & $.59^{* * * *}$ & $.50^{* * * *}$ & -.09 & -.09 & $-.16^{*}$ \\
\hline 2. FU1 self-report AUD & 179 & $2.53(2.37)$ & $0-12$ & & - & $.62^{* * * *}$ & $.53^{* * *}$ & -.09 & -.03 & -.08 \\
\hline 3. FU2 self-report AUD & 189 & $2.39(2.36)$ & $0-12$ & & & - & $.69^{* * *}$ & $-.19^{*}$ & -.05 & -.07 \\
\hline 4. SADYSM self-report AUD & 190 & $2.63(2.22)$ & $0-12$ & & & & - & $-.19^{* *}$ & -.10 & -.12 \\
\hline 5. Involvement & 190 & $4.36(0.88)$ & $1-5^{1}$ & & & & & - & $.37^{* * *}$ & $.40^{* * *}$ \\
\hline 6. Structure & 190 & $3.88(0.95)$ & $1-5^{1}$ & & & & & & - & $.36^{* * *}$ \\
\hline 7. Knowledge & 190 & $4.05(0.96)$ & $1-5^{1}$ & & & & & & & - \\
\hline
\end{tabular}

Note AUD $=$ alcohol use disorder; $\mathrm{BL}=$ baseline; FU1 $=$ follow-up $1 ; \mathrm{FU} 2=$ follow-up $2 .{ }^{1} 1$ = almost never, $5=$ almost always.

${ }^{*} p<.05 .{ }^{* *} p<.01 .{ }^{* * *} p<.001$. 
Table 3

Model Fit Statistics and Profile Distribution by Number of Latent Profiles

\begin{tabular}{|c|c|c|c|c|c|c|c|c|c|}
\hline \multirow{2}{*}{ Profile } & \multirow{2}{*}{ Log-likelihood } & \multirow{2}{*}{ AIC } & \multirow{2}{*}{$\mathrm{BIC}$} & \multirow{2}{*}{ SABIC } & \multirow{2}{*}{ BLRT $p$-value } & \multirow{2}{*}{ Entropy } & \multicolumn{3}{|c|}{$n$ per profile ${ }^{1}$} \\
\hline & & & & & & & 1 & 2 & 3 \\
\hline 1 & -765.74 & 1543.48 & 1562.97 & 1543.96 & - & - & $190(100)$ & - & - \\
\hline 2 & -711.79 & 1443.58 & 1476.05 & 1444.37 & .010 & .87 & $34(18)$ & $156(82)$ & - \\
\hline 3 & -696.77 & 1421.55 & 1467.00 & 1422.66 & .010 & .83 & $26(14)$ & $33(17)$ & $131(69)$ \\
\hline
\end{tabular}

Note. The selected model is bolded. AIC = akaike information criteria; $\mathrm{BIC}=$ bayesian information criteria; $\mathrm{SABIC}=$ sample-size adjusted $\mathrm{BIC} ; \mathrm{BLRT}=$ bootstrapped likelihood ratio test. ${ }^{1}$ Percentages are reported under brackets. 
Table 4

Means (Standard Deviations) and Tests of Mean Differences for Continuous Indicator Variables by Profile of Parenting

\begin{tabular}{|c|c|c|c|c|}
\hline \multirow[b]{2}{*}{ Variable } & \multicolumn{3}{|l|}{ Profile } & \multirow[b]{2}{*}{$F$-value } \\
\hline & $\begin{array}{l}\text { Low Support } \\
(\mathrm{n}=26)\end{array}$ & $\begin{array}{l}\text { Uninformed } \\
(\mathrm{n}=33)\end{array}$ & $\begin{array}{l}\text { Optimal } \\
(\mathrm{n}=131)\end{array}$ & \\
\hline Involvement & $2.62(0.71)^{\mathrm{a}}$ & $4.38(0.50)^{b}$ & $4.69(0.50)^{\mathrm{c}}$ & $233.4^{* * *}$ \\
\hline Structure & $3.12(1.04)^{\mathrm{a}}$ & $3.47(0.92)^{\mathrm{a}}$ & $4.14(0.81)^{b}$ & $38.83^{* * *}$ \\
\hline Knowledge & $3.21(0.80)^{\mathrm{a}}$ & $2.70(0.65)^{b}$ & $4.56(0.50)^{c}$ & $154.00^{* * *}$ \\
\hline
\end{tabular}

Note. Means with different alphabetic superscripts within a row significantly differ at $p<.01$ (post hoc comparisons using Tukey's test). ${ }^{*} p<.05 .{ }^{* *} p<.01 .{ }^{* * *} p<.001$. 
Table 5

Parameter Estimates for Latent Growth Curve Models of AUD

\begin{tabular}{|c|c|c|c|}
\hline & Model $1^{\mathrm{a}}$ & Model $2^{\mathrm{b}}$ & Model $3^{c}$ \\
\hline \multicolumn{4}{|l|}{ Intercept } \\
\hline Estimate & $2.30^{* * * *}$ & $2.07^{* * *}$ & $2.10^{* * *}$ \\
\hline Variance & $4.26^{* * *}$ & $4.16^{* * *}$ & $4.16^{* * *}$ \\
\hline \multicolumn{4}{|l|}{ Slope } \\
\hline Estimate & 0.06 & $0.29^{* *}$ & 0.04 \\
\hline Variance & $0.10^{* * *}$ & $0.09^{* * *}$ & $0.09^{* * *}$ \\
\hline Covariance intercept-slope & $-.31^{* * *}$ & $-.30^{* * *}$ & $-.30^{* * *}$ \\
\hline \multicolumn{4}{|l|}{ Intercept on profile } \\
\hline Uninformed vs. Low Support & - & 1.10 & - \\
\hline Optimal vs. Low Support & - & 0.03 & - \\
\hline Low Support vs. Optimal & - & - & -0.03 \\
\hline Uninformed vs. Optimal & - & - & $1.06^{*}$ \\
\hline \multicolumn{4}{|l|}{ Slope on profile } \\
\hline Uninformed vs. Low Support & - & $-0.35^{* *}$ & - \\
\hline Optimal vs. Low Support & - & $-0.25^{* *}$ & - \\
\hline Low Support vs. Optimal & - & - & $0.25^{* *}$ \\
\hline Uninformed vs. Optimal & - & - & -0.10 \\
\hline
\end{tabular}

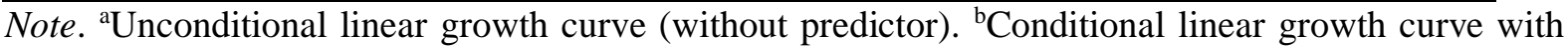
parenting profile membership as predictor of intercept and slope means (reference group $=$ Low Support). ${ }^{\mathrm{c}}$ Conditional linear growth curve with parenting profile membership as predictor of intercept and slope means (reference group $=$ Optimal) .

${ }^{*} p<.05 .{ }^{* *} p<.01 .{ }^{* * *} p<.001$. 


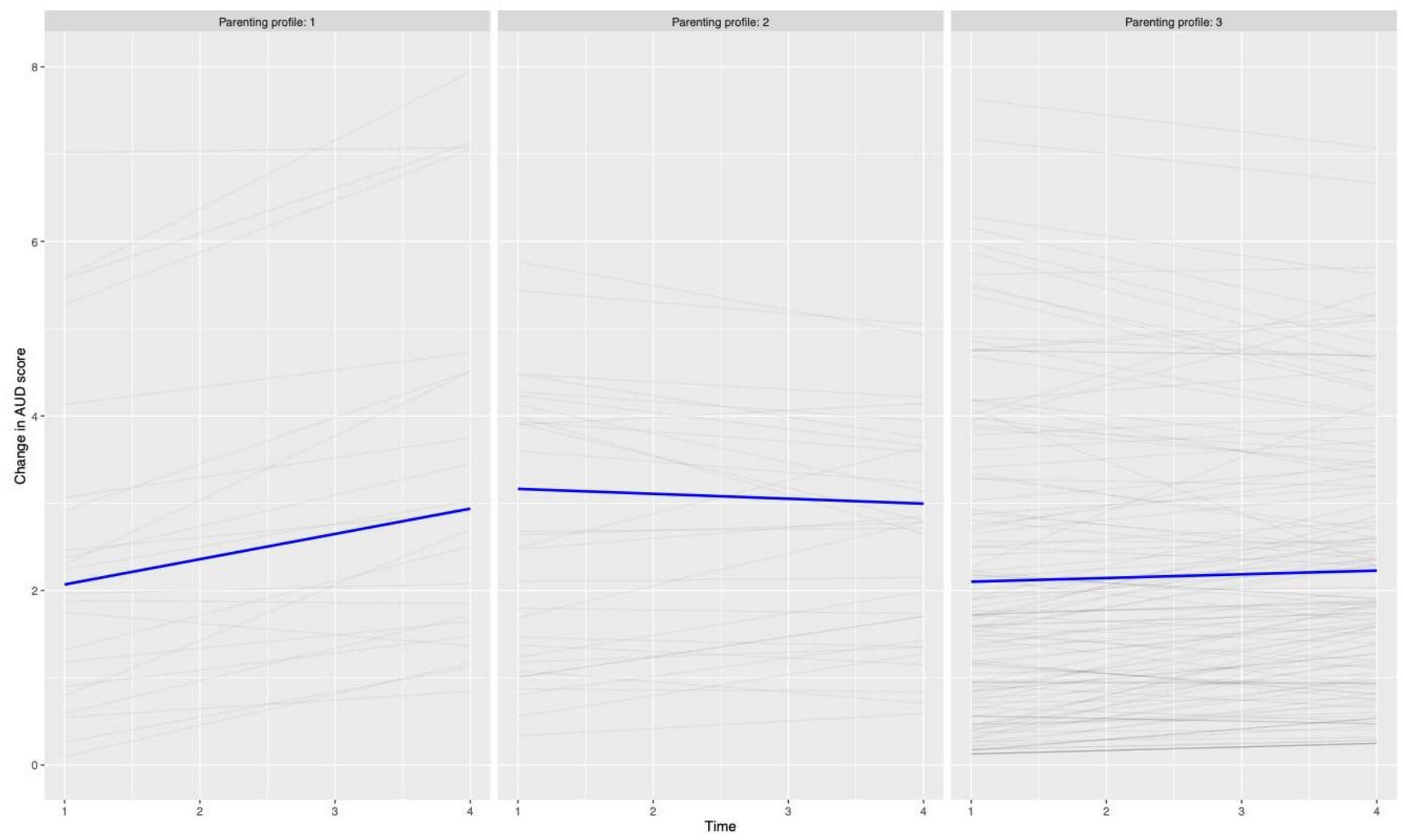

Figure 1. Average changes in participants' AUD score by parenting profiles $(1=$ Low Support, $2=$ Uninformed, $3=$ Optimal $)$. 